\title{
Yoğun Bakım Hemşirelerinin Kas İskelet Ağrılarını Etkileyen Değişkenler ve Ergonomik Risk İlişkisinin İncelenmesi
}

\author{
Ebru ARSLAN ÖZDEMİR ${ }^{1}$, Özlem ÖRSAL [0] $^{2}$
}

\section{öz}

Amaç: Çalışmamızın amacı yoğun bakım ünitelerinde çalışan hemşirelerde görülen kas iskelet sistemi ağrılarını etkileyen değişkenleri ve bu değişkenlerin ergonomik risklerle ilişkisini incelemektir.

Gereç ve Yöntemler: Araştırma bir devlet hastanesinin yoğun bakım ünitelerinde çalışan 98 hemşire ile yürütülmüştür. Veriler toplanırken "Tanımlayıcı Bilgiler Formu" ve "Genişletilmiş Nordic Kas İskelet Sistemi Sorgusu" anket yoluyla, "REBA (Rapid Entire Body Assessment-Hızlı Tüm Vücut Değerlendirmesi) Çalışan Değerlendirme Formu” ise gözlem yoluyla toplanmıştır. Genişletilmiş Nordic Kas-İskelet Sistemi Ağrı Sorgusu ile hemşirelerin tüm vücut bölgelerinde sahip oldukları ağrıları ve REBA yöntemi ile ergonomiksel risk düzeyi tespit edilmiştir. Analizler ki - kare ve Mann Whitney-U testi ile değerlendirilmiştir. İstatistiksel anlamlılık değeri $\mathrm{p}<, 05$ olarak alınmıştır. Çalışmanın yürütülebilmesi için gerekli etik kurul ve kurum izinleri ve katılımcılardan da gönüllü onamı alınmıştır.

Bulgular: Çalışmamızda hemşirelerin en sık ağrı yaşadıkları üç lokalizasyon; \%56,1 ile bel, \%41,8 ile sırt ve \%39,8 ile boyun bölgeleri olarak saptanmıştır. Hemşirelerin kas iskelet sistemindeki ağrı lokalizasyonlarından boyun, omuz, sırt ve ayak-ayak bileğinde ağrısı olanların REBA puanları daha yüksek bulunmuştur $(\mathrm{p}<, 05)$.

Sonuç: Hemşirelerde maruz kaldıkları fiziksel zorlanmalar sonucunda kas iskelet rahatsılıkları görülebilmektedir. Çalışma ortamının ergonomik açıdan düzenlenmesi, hemşirelere doğru duruş, çalışma pozisyonu konularını içeren periyodik eğitim programlarının düzenlenmesi ve rahatsızlıklarına uygun egzersiz programlarına yönlendirilmeleri önerilmektedir.

Anahtar Kelimeler: Hemşirelik; kas-iskelet ağrısı; ergonomik

\section{Investigation of The Relationship Between Variables and Ergonomic Risk Related to Musculoskeletal Pains of Intensive Care Nurses}

\begin{abstract}
Aim: The aim of our study is to examine the variables affecting musculoskeletal pain seen in nurses working in intensive care units and the relationship of these variables with ergonomic risks.

Material and Methods: The research was conducted with 98 nurses working in the intensive care units of a state hospital. While collecting the data, "Descriptive Information Form" and "Extended Nordic Musculoskeletal System Inquiry" questionnaire were collected and "REBA (Rapid Entire Body Assessment-Fast Whole Body Evaluation) Employee Evaluation Form" was collected through observation. With the extended Nordic musculoskeletal pain question, nurses' pain in all body parts and ergonomic risk level were determined by REBA method. Analyzes were evaluated by chi - square and Mann Whitney-U test. Statistical significance value was taken as $p<, 05$. The ethical committee and institution permissions required for conducting the study and voluntary consent were obtained from the participants.

Results: In our study, three localizations where nurses experience the most frequent pain; Waist with $56.1 \%$, back with $41.8 \%$ and neck regions with $39.8 \%$. The pain localization of the muscles of the nurses, the height, shoulder, back and feet-ankle pain of those who have higher REBA scores.

Conclusion: Muscle skeletal disorders can be seen as a result of the physical stresses experienced by the nurses. It is recommended that the work environment should be arranged in an ergonomic way and the nurses should be provided with periodic training programs including correct posture, working position and directing them to exercise programs appropriate for their discomfort.
\end{abstract}

1 Eskişehir Osmangazi Üniversitesi, Sağlık Bilimleri Enstitüsü, Hemşirelik Bölümü, Eskişehir, Türkiye

2 Eskişehir Osmangazi Üniversitesi, Sağlık Bilimleri Fakültesi, Hemşirelik Bölümü, Eskişehir, Türkiye 
Keywords: Nursing; musculoskeletal pain; ergonomic

\section{GIRIS}

Dünyadaki insanların yarısı ekonomik açıdan aktiftir ve bu insanlar günlük yaşamlarının en az üçte birini iş yerlerinde geçirmektedirler. İş yerlerinde, çalışılan şartlardan ve yürütülen işlerden kaynaklanan, sağlı̆ğ olumsuz yönde etkileyen bazı riskler ve faktörler bulunmaktadır (1-3). Bu risklerin sonucunda meydana gelebilen kazalar; malzeme kayılarına ve iş ekipmanı hasarlarına neden olduğu gibi çalışanların yaralanmalarına, hastalanmalarına ve ölümlerine de neden olabilmektedir (4).

Hemşireler sağlıklarını olumsuz etkileyebilecek uzun ve aralıksız çalışma süreleri, çalışma ortamlarında yaşadıkları fiziksel ve psikolojik sorunlar gibi çeşitli mesleki risklerle karşı karşıya kalırlar $(5,6)$. Dünya'daki hemşire iş gücündeki azalmanın en önemli nedeninin sağlıklı olmayan çalışma ortamı olduğu belirtilmektedir (7).

Yoğun bakım ünitelerinde izlem, bakım ve tedavileri uygulanan hastalar genel olarak durumları stabil olmayan, çoğunlukla uzun ya da kısa süreli mobilizasyonları sınırlandırılmış ya da yatağa bağımlı hastalardan oluşmaktadır $(8,9)$. Bu hastaların, pozisyon değişikliği, soyunma, giyinme, beslenme, banyo ve tuvalet ihtiyaçları gibi günlük yaşam aktivitelerinin neredeyse tamamı hemşireler tarafından karşılanmaktadır $(10,11)$. Ayrıca bu hastaların sahip oldukları; intravenöz, santral venöz, arter ve diyaliz kataterlerinin, stomalarının, uzun süre yatışa ya da ekipmana bağlı gelişen bası yaralarının, ameliyat ya da travma sonrası meydana gelen yaralarının ve insizyonların pansumanlarının düzenli aralıklarla değişiminden sorumlu hemşireler bu uygulamalar esnasinda uzun süre ayakta, uygun olmayan ve sabit pozisyonda kalmaktadırlar (12, 13). Yoğun bakım hemşirelerinin hastanın doğrudan bakımıyla ilgilenmeleri nedeniyle fiziksel iş yükleri diğer birimde çalışan meslektaşlarına göre daha fazladır (14). Sonuç olarak, bu uygulamalar yoğun bakım ünitelerinde çalışan hemşirelerde ergonomik risklere bağlı kas-iskelet problemlerinin görülmesine neden olabilmektedir.

Yoğun bakım hemşirelerinde görülen kas iskelet sistemi ağrıları hemşirelerin yaşam kalitelerini olumsuz yönde etkilemekte olup, erken emeklilik, rapor alınması gibi çalışma yaşamını etkileyecek olumsuz sonuçları da bulunmaktadır. Ayrıca bu durum bakım alan bireyin kaliteli bakım alamamasına da sebep olabilmektedir $(6,15,16,17)$.

Çalışmamızdan elde edilecek sonuçların mevcut durum hakkında bilgi vereceği, ergonomik risk analizine göre ergonomik düzenleme yapılması sonucunda işe bağlı kas iskelet sistemi (KIS) ağrılarını azaltmada katkı sağlayacağı ve gelecekte yürütülecek çalışmalara da yol gösterici olacağı düşünülmektedir.

Çalışmamızın amacı yoğun bakım ünitelerinde çalışan hemşirelerde görülen kas iskelet sistemi ağrılarını etkileyen değişkenleri ve bu değişkenlerin ergonomik risklerle ilişkisini incelemektir.

$\mathrm{Bu}$ amaca yönelik olarak aşağıdaki sorulara yanıt aranmaktadır;
1. Yoğun bakım ünitelerinde çalışan hemşirelerin sahip oldukları kas iskelet ağrıları ile sosyodemografik özellikleri arasında bir ilişki var mıdır?

2. Yoğun bakım ünitelerinde çalışan hemşirelerin sahip oldukları kas iskelet ağrıları ile çalışma özellikleri arasında bir ilişki var mıdır?

3. Yoğun bakım ünitelerinde çalışan hemşirelerin sahip oldukları kas iskelet ağrıları ile karşı karşıya kaldıkları ergonomik riskler arasında bir ilişki var mıdır?

\section{GEREÇ VE YÖNTEMLER \\ Araştırmanın Tipi}

$\mathrm{Bu}$ araştırma tamsayım örnekleme yöntemi ile yapılmış kesitsel ve tanımlayıcı tipte bir araştırmadır.

\section{Araştırmanın Evreni ve Örneklemi}

Çalışma evrenini Şubat-Nisan 2017 tarihleri arasında bir devlet hastanesinin 3. basamak genel yoğun bakım (cerrahi yoğun bakım), 2. basamak genel yoğun bakım, koroner yoğun bakım, göğüs yoğun bakım ve nöroloji yoğun bakım olmak üzere beş yoğun bakım ünitesinde çalışmakta olan 101 hemşire oluşturmaktadır. 3. Basamak genel yoğun bakım ünitesinde bakım gören hastaların çoğu yatağa bağımlı ve mekanik solunum cihazı ihtiyacı olan hastalardan oluşmakta olup günlük yaşam aktivitelerinin neredeyse tamamında hemşirelere bağımlıdırlar. Bu bağımlılık 2. basamak genel yoğun bakım, nöroloji yoğun bakım, göğüs yoğun bakım ve koroner yoğun bakım ünitesine doğru giderek azalmaktadır. Çalışmada örneklem seçimi yapılmamış olup, evrenin tamamına ulaşılması amaçlanmıştır. Çalışma araştırmaya katılmaya gönüllü olan 98 hemşire (katılım oranı: \% 97.02) üzerinde yürütülmüştür.

Veri Toplama Araçları ve Verilerin Toplanması

Veriler toplanırken "Tanımlayıcı Bilgiler Formu" ve "Genişletilmiş Nordic Kas İskelet Sistemi Sorgusu" anket yoluyla, "REBA (Rapid Entire Body Assessment-Hızlı Tüm Vücut Değerlendirmesi) Çalışan Değerlendirme Formu" gözlem yoluyla toplanmıştır.

Tanımlayıcı Bilgiler Formu: Araştırmacılar tarafından literatür taranarak oluşturulan yaş, cinsiyet, beden kitle indeksi (BKI), çalıştıkları yoğun bakım ünitelerini sorgulayan dört sorudan oluşan bir formdur.

Genişletilmiş Nordic Kas-İskelet Sistemi Ağrı Sorgusu (İskandinav Kas-İskelet Sistemi Sorgusu): Türkçe geçerlilik güvenilirlik çalışması Kahraman, Genç ve Göz tarafından yapılmış olup, boyun, omuz, sırt, dirsek, el/el bileği, bel, kalça/uyluk, diz, ayak/ayak bileği olmak üzere dokuz bölgeyi anatomik olarak gösteren bir şekil üzerinde ağrının olup olmadığını, ağrının ilk başladığı yaşı, ağrı nedeniyle hastaneye yatma ve görev değiştirme durumunu, son on iki ay, bir ay ve yedi gün içinde rahatsızlıkların başlangıcı, prevalansı ve sonucu ile ilgili güvenilir bilgi sağlayan, kendi kendine doldurulabilen 12 soruluk bir formdur $(18,19)$.

Çalışmamızda uzun süreli ağrının varlığı değerlendirilmek istendiği için yapılan analizlerde hemşirelerin son on iki ay içerisinde hissettikleri kas iskelet sistemi ağrılarının verileri kullanılmıştır.

REBA (Rapid Entire Body Assessment-Hızlı Tüm Vücut Değerlendirmesi) Çalışan Değerlendirme Formu: Tüm vücut aktivitelerinin hem sabit hem hareketli hızlı postür analizini kolaylaştırmak için Hignett ve McAtamney adlı iki ergonomist tarafindan REBA 
tasarlanmıştır. REBA ile bilek, ön kol, dirsek, omuz, boyun ve bel gibi vücudun üst uzuvlarına ek olarak gövde, sırt, bacaklar ve dizler değerlendirmeye alınabilmekte, analiz edilmek istenilen duruş veya hareketin neden olduğu toplam risk sayısal olarak ifade edilebilmektedir. REBA'dan elde edilen puanlar ile risk seviyesi değerlendirilebilirken, ayrıca herhangi bir aktivite / girişimin gereklilik derecesi de değerlendirilebilmektedir. REBA skorundan elde edilen puan 1-15 arasında değişmektedir. REBA yöntemi ile statik ve dinamik tüm vücut faaliyetleri esnasında çalışanın duruşu analiz edilerek mesleki kas ve iskelet rahatsızlıklarına sebep olabilecek çalışma duruşlarının saptanması ve gerekli önlemlerin alınabilmesine yol gösteren gözleme dayalı bir duruş analizi metodudur (20). REBA'nın Türkçe geçerlilik güvenilirliği henüz yapılmamış olup, ülkemizde risk ölçümü yapılan çalışmalarda kullanılmaktadır $(21,22)$.

REBA yönteminde çalışma ortamında sık tekrarı yapılan, çalışanı zorlayan, uygulanmasında fiziksel güç gerektiren uygulama seçilerek duruş analizi yapılır. REBA yönteminde analiz edilecek duruş esnasında boynun, gövdenin, bacakların, üst kol ve alt kolun anlık duruşu dikkate alınarak ve duruşlara puanlar vermek yoluyla bir risk skoru elde edilir (20).

Çalışmanın Uygulaması: Tanımlayıcı Bilgiler Formu ve Genişletilmiş Nordic Kas-İskelet Sistemi Ağrı Sorgusu hemşireler tarafından doldurulmuştur. REBA formu ise araştırmacı tarafından hemşirelerin mesai saatleri içerisinde doldurulmuştur. $\mathrm{Bu}$ çalışmada hemşirelerin vardiyada en çok tekrar ettiği uygulamalardan biri olan hastaya yatak içi pozisyon verme uygulaması seçilerek duruş analizi yapılmıştır. 3 uygulamanın (mesainin başında, ortasında ve sonunda) ortalaması alınıp bir REBA puanı elde edilmiştir. Hemşirelere onam alınırken gözlemlenecekleri konusunda bilgi verilmiş ancak gözlem esnasında doğru sonuçlara ulaşabilmek için haber verilmemiştir. REBA puanınn hesaplanması Şekil 1 'de gösterilmiştir.

\section{İstatistiksel Analiz}

Analizler IBM SPSS Statistics 20 paket programı kullanılarak Ki-Kare ve Mann Whitney-U testi ile değerlendirilmiştir. İstatistiksel anlamlılık değeri $\mathrm{p}<, 05$ olarak alınmıştır.

\section{Araştırmanın Etik Yönü}

Çalışmanın yürütülebilmesi için Eskişehir Osmangazi Üniversitesi Girişimsel Olmayan Klinik Araştırmalar Etik Kurulundan 04.01.2017 tarih ve 80558721/G-12 say1l onay ve Bursa İli Kamu Hastaneleri Birliği Genel Sekreterliğinden 16.01.2017 tarih ve 1303 sayılı kurum izni alınmıştır. Kullanılan ölçekler için, ölçek sahiplerinden e-posta yoluyla izin alınmıştır. Hemşireler çalışma konusunda bilgilendirildikten sonra yazılı onamları alınmış, anket formları gözlem altında hemşirelerin kendisi tarafından, REBA formu ise hemşireler gözlenerek araştırmacılar tarafından doldurulmuştur.

\section{BULGULAR}

Araştırma kapsamına alınan hemşirelerin yaş ortalaması $32.50 \pm 7.3$ (min. 20; maks. 49) olup, \%82.7'si ( $\mathrm{n}=81)$ kadındır. Hemşirelerin beden kitle indeksleri $23.51 \pm 3.36$ (min.17.01; maks.38.05)'dır. Hemşirelerin \%3.1'i (n=3) zayıf, \%67.3'ü (n=66) normal kilolu, \%24.5'i (n=24) fazla kilolu ve \%5.1'i $(n=4)$ obezdir. Hemşirelerin \%46.9'u (n=46) 3. basamak GYB, \%29.6's1 (n=29) 2. basamak GYB, \%9.2'si (n=9) Koroner YB, \%6.1'i (n=6) Göğüs YB ve \%8.2'si $(n=8)$ Nöroloji YB'da çalışmaktadır (Tablo 2).

Genişletilmiş Nordic Kas-İskelet Sistemi Anketine göre son 12 ay içerisinde hemşirelerin kas iskelet sisteminin çeşitli lokalizasyonlarında görülen ağrı prevelansları ile yaş grupları, cinsiyetleri, BKİ'leri, çalıştıkları vardiyalar arasında istatistiksel olarak anlamlı bir farklılık saptanmamıştır (her biri için; $\mathrm{p}>$,05). 3. basamak genel yoğun bakım ünitesinde çalışan hemşirelerin \%56,5'inde $(n=26)$ omuz ağrısı $(p<, 001)$, koroner yoğun bakımda çalışan hemşirelerin \%55,6'sında $(n=5)$ ayak bileği/ayak ağrısı ( $<<, 05)$ diğer birimlerde çalışan hemşirelere göre daha yüksek saptanmıştır (her biri için; p <,05, Tablo 2).

REBA puanlarının risk seviyesi ve önlem gereklilikleri Tablo 1'de gösterilmiştir.

Tablo 1. REBA skorlarının değerlendirilmesi

\begin{tabular}{|c|c|c|}
\hline $\begin{array}{l}\text { REBA } \\
\text { puanı }\end{array}$ & Risk Seviyesi & Önlem \\
\hline 1 & $\begin{array}{l}\text { Kabul edilebilir } \\
\text { risk }\end{array}$ & Gerekli değil \\
\hline $2-3$ & Düşük risk & Gerekli olabilir \\
\hline $4-7$ & Orta risk & Gerekli \\
\hline $8-10$ & Yüksek risk & $\begin{array}{l}\text { Kisa zaman içinde } \\
\text { gerekli }\end{array}$ \\
\hline $11-15$ & Çok yüksek risk & Hemen gerekli \\
\hline
\end{tabular}

Hemşirelerden kas iskelet sistemlerinde ağrı şikayetleri var olanların, lokalizasyonlarından boyun, omuz, sırt ve ayak-ayak bileğinde ağrısı olanların REBA puanları daha yüksektir (her biri için; $\mathrm{p}<, 05$, Tablo 3 ). Hemşirelerin kas iskelet sistemindeki ağrı lokalizasyonlarından dirsek, elel bileği, bel, kalça ve diz bölgelerindeki ağrı şikayetleri ile REBA puanları arasında istatistiksel olarak anlamlı bir fark saptanmamıştır (her biri için; p>,05, Tablo 3). 


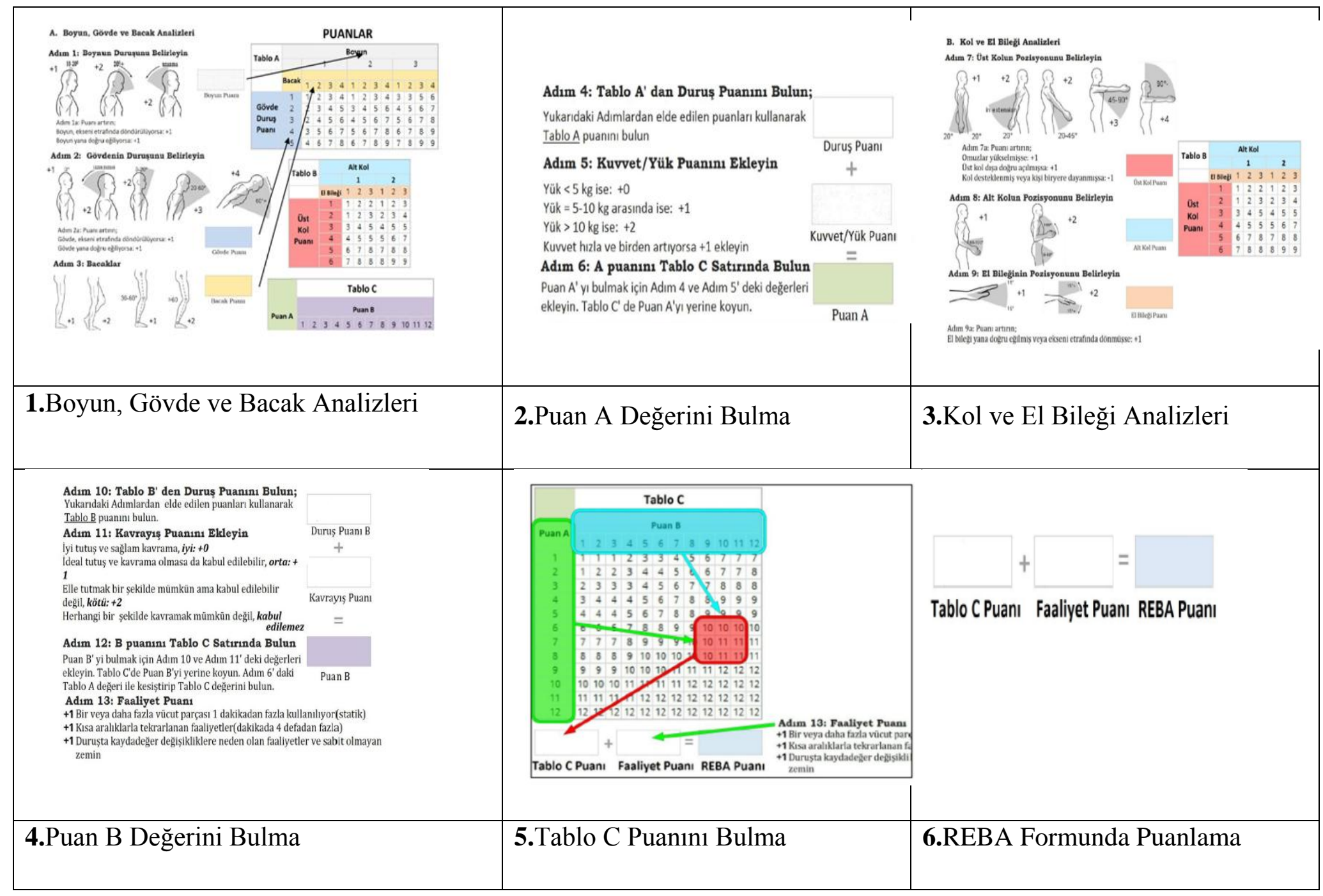

Şekil 1. REBA puanının hesaplanması 


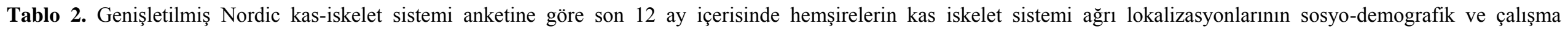
özelliklerine göre dağılımı

\begin{tabular}{|c|c|c|c|c|c|c|c|c|c|c|}
\hline \multirow{2}{*}{ Değişkenler } & \multirow{2}{*}{$\mathbf{n}$} & Boyun & Omuz & Sirt & Dirsek & El/EI Bileği & Bel & Kalça & Diz & \multirow[t]{2}{*}{ Ayak Bileği/Ayak } \\
\hline & & n(\%) & $\mathbf{n}(\%)$ & n(\%) & n(\%) & n(\%) & n(\%) & n(\%) & n(\%) & \\
\hline \multicolumn{11}{|l|}{ Yaş } \\
\hline$<24$ yaş & 19 & $7(17,9)$ & $8(25,0)$ & $11(26,8)$ & $1(33,0)$ & $3(23,1)$ & $10(18,2)$ & $3(23,1)$ & $7(24,1)$ & $11(35,5)$ \\
\hline $25-29$ yaş & 19 & $10(25,6)$ & $8(25,0)$ & $8(19,5)$ & $0(0,0)$ & $4(30,8)$ & $10(18,2)$ & $4(30,8)$ & $7(24,1)$ & $6(19,4)$ \\
\hline 30-34 yaş & 18 & $9(23,1)$ & $7(21,9)$ & $10(24,4)$ & $0(0,0)$ & $0(0,0)$ & $13(23,6)$ & $3(23,1)$ & $4(13,8)$ & $4(12,9)$ \\
\hline $35-39$ yaş & 23 & $5(12,8)$ & $5(15,6)$ & $8(19,5)$ & $2(66,7)$ & $2(15,4)$ & $13(23,6)$ & $0(0,0)$ & $5(17,2)$ & $7(22,6)$ \\
\hline \multirow[t]{2}{*}{$>40$ yaş } & 19 & $8(20,5)$ & $4(12,5)$ & $4(9,8)$ & $0(0,0)$ & $4(30,8)$ & $9(16,4)$ & $3(23,1)$ & $6(20,7)$ & $3(9,7)$ \\
\hline & Ki kare; $p$ & 5,$330 ; .255$ & 4,$271 ; .371$ & 7,$249 ; .123$ & 4,$539 ; .338$ & 5,$278 ; .260$ & 2,$675 ; .614$ & 4,$911 ; .297$ & 2,$145 ; .709$ & 9,$017 ; .061$ \\
\hline \multicolumn{11}{|l|}{ Cinsiyet } \\
\hline Kadın & 81 & $35(43,2)$ & $28(34,6)$ & $37(457)$ & $3(3,7)$ & $11(13,6)$ & $48(59,3)$ & $12(14,8)$ & $23(28,4)$ & $26(32,1)$ \\
\hline \multirow[t]{2}{*}{ Erkek } & 17 & $4(23,5)$ & $4(23,5)$ & $4(235)$ & $0(0,0)$ & $2(11,8)$ & $7(41,2)$ & $1(5,9)$ & $6(35,3)$ & $5(29,4)$ \\
\hline & Ki kare; $p$ & 2,$272 ; .132$ & 0,$779 ; .378$ & $2833 ; .092$ & 0,$650 ; .420$ & 0,$040 ; .841$ & 1,$866 ; .172$ & 0,$974 ; .324$ & 0,$321 ; .571$ & 0,$047 ; .829$ \\
\hline \multicolumn{11}{|l|}{ BKI ** } \\
\hline$<24.99$ & 69 & $29(74,4)$ & $23(71,9)$ & $28(683)$ & $3(100,0)$ & $11(84,6)$ & $40(72,7)$ & $11(84,6)$ & $19(65,5)$ & $25(80,6)$ \\
\hline \multirow[t]{2}{*}{$>25.00$} & 29 & $10(25,6)$ & $9(28,1)$ & $13(317)$ & $0(0,0)$ & $2(15,4)$ & $15(27,3)$ & $2(15,4)$ & $10(34,5)$ & $6(19,4)$ \\
\hline & Ki kare; $p$ & 0,$485 ; .486$ & 0,$049 ; .825$ & $0151 ; .697$ & 1,$301 ; 254$ & 1,$452 ; .228$ & 0,$324 ; .569$ & 1,$452 ; .228$ & 0,$473 ; .492$ & 2,$281 ; .131$ \\
\hline \multicolumn{11}{|c|}{ Çalışılan yoğun bakım ünitesi } \\
\hline 3.basamak GYB & 46 & $22(47,8)$ & $26(56,5)$ & $25(54,3)$ & $2(4,3)$ & $7(15,2)$ & $26(56,5)$ & $9(19,6)$ & $17(37,0)$ & $19(41,3)$ \\
\hline 2.basamak GYB & 29 & $11(37,9)$ & $4(13,8)$ & $8(27,6)$ & $1(3,4)$ & $4(13,8)$ & $12(41,4)$ & $3(10,3)$ & $8(27,6)$ & $6(20,7)$ \\
\hline Koroner YB & 9 & $3(33,3)$ & $2(22,2)$ & $2(22,2)$ & $0(0,0)$ & $1(11,1)$ & $7(7738)$ & $0(0,0)$ & $2(22,2)$ & $5(55,6)$ \\
\hline Göğüs YB & 6 & $2(33,3)$ & $0(0,0)$ & $3(50,0)$ & $0(0,0)$ & $0(0,0)$ & $5(83,3)$ & $1(16,7)$ & $1(16,7)$ & $0(0,0)$ \\
\hline \multirow[t]{2}{*}{ Nöroloji YB } & 8 & $1(12,5)$ & $0(0,0)$ & $3(37,5)$ & $0(0,0)$ & $1(12,5)$ & $5(62,5)$ & $0(0,0)$ & $1(12,5)$ & $1(12,5)$ \\
\hline & Ki kare; p & 4,$029 ; .402$ & 23,$841 ; .000$ & 7,028;.134 & 0,998;.910 & 1,$117 ; .892$ & 6,$213 ; .184$ & 4,$462 ; .347$ & 3,$091 ; .543$ & 10,$107 ; \mathbf{0 3 9}$ \\
\hline Toplam & 98 & $39(100,0)$ & $32(100,0)$ & $41(100,0)$ & $3(100,0)$ & $13(100,0)$ & $55(100,0)$ & $13(100,0)$ & $29(100,0)$ & $31(100,0)$ \\
\hline
\end{tabular}


Tablo 3: Hemşirelerin REBA puan ortancalarının genişletilmiş Nordic kas-iskelet sistemi anketine göre son 12 ay içerisinde hemşirelerin kas iskelet sistemi ağrılarına ve ağrı lokalizasyonlarına göre dağılımı

\begin{tabular}{|c|c|c|c|}
\hline Ağrı varlığı ve lokalizasyonu & $\mathbf{n}(\%)$ & $\begin{array}{c}\text { REBA puan } \\
\text { Medyan } \\
\text { (min.- maks.) }\end{array}$ & $\begin{array}{l}\text { İstatistiksel analiz } \\
\text { Mann Whitney-U; p }\end{array}$ \\
\hline \multicolumn{4}{|l|}{ Kas iskelet sisteminde ağrı şikayeti } \\
\hline Yok & $7(7.1)$ & $5,00(5,00-9,00)$ & \multirow{2}{*}{506,$000 ;, \mathbf{0 0 8}$} \\
\hline Var & $91(92,9)$ & $9,00(5,00-13,00)$ & \\
\hline \multicolumn{4}{|l|}{ Boyun bölgesinde } \\
\hline Yok & $59(60,2)$ & $8,00(5,00-11,00)$ & \multirow{2}{*}{1,$502 ;, 009$} \\
\hline Var & $39(39,8)$ & $10,00(5,00-13,00)$ & \\
\hline \multicolumn{4}{|l|}{ Omuz bölgesinde } \\
\hline Yok & $66(67,3)$ & $8,50(5,00-11,00)$ & \multirow{2}{*}{1,$499 ;, \mathbf{0 0 1}$} \\
\hline Var & $32(32,7)$ & $10,00(7,00-13,00)$ & \\
\hline \multicolumn{4}{|l|}{ Surt bölgesinde } \\
\hline Yok & $57(58,1)$ & $9,00(5,00-13,00)$ & \multirow{2}{*}{1,$435 ;, 049$} \\
\hline Var & $41(41,9)$ & $9,00(7,00-11,00)$ & \\
\hline \multicolumn{4}{|l|}{ Dirsek } \\
\hline Yok & $95(96,9)$ & $9,00(5,00-13,00)$ & \multirow{2}{*}{233,$000 ;, 062$} \\
\hline Var & $3(3,1)$ & $10,00(10,00-11,00)$ & \\
\hline \multicolumn{4}{|l|}{ El - El bileği } \\
\hline Yok & $85(86,7)$ & $9,00(5,00-11,00)$ & \multirow{2}{*}{657,$500 ;, 262$} \\
\hline Var & $13(13,3)$ & $9,00(5,00-13,00)$ & \\
\hline \multicolumn{4}{|l|}{ Bel bölgesinde } \\
\hline Yok & $43(43,8)$ & $9,00(5,00-11,00)$ & \multirow{2}{*}{1,$213 ;, 821$} \\
\hline Var & $55(56,2)$ & $9,00(5,00-13,00)$ & \\
\hline \multicolumn{4}{|l|}{ Kalça bölgesinde } \\
\hline Yok & $85(86,7)$ & $9,00(5,00-13,00)$ & \multirow{2}{*}{ 707,000; ,099 } \\
\hline Var & $13(13,3)$ & $10,00(7,00-11,00)$ & \\
\hline \multicolumn{4}{|l|}{ Diz } \\
\hline Yok & $69(70,4)$ & $9,00(5,00-11,00)$ & \multirow{2}{*}{1,$117 ;, 355$} \\
\hline Var & $29(29,6)$ & $9,00(5,00-13,00)$ & \\
\hline \multicolumn{4}{|l|}{ Ayak-Ayak bileği } \\
\hline Yok & $67(68,3)$ & $9,00(5,00-11,00)$ & \multirow{3}{*}{1,$292 ;, \mathbf{0 4 8}$} \\
\hline Var & $31(31,7)$ & $10,00(5,00-13,00)$ & \\
\hline Toplam & $98(100)$ & $9,00(5,00-13,00)$ & \\
\hline
\end{tabular}




\section{TARTISSMA}

Kişilerde 30 yaşından sonra kassal kuvvetin her on yılda bir \%10-15 oranında azalmaya başladığı belirtilmektedir (19). Bu çalışmada hemşirelerin son 12 aydaki kas-iskelet sistemi ağrı lokalizasyonları ile yaş grupları arasında anlamlı bir ilişki saptanmamıştır (Tablo 2). Literatürde yaş ve kas iskelet sistemi rahatsılılıları arasında anlamı bir ilişki olmadığını belirten çalışmalar olduğu gibi (18, 22, 23), yaş ve çalışma süresi daha fazla olan hemşirelerin daha fazla kas iskelet sistemi rahatsızlıklarına sahip olduklarını bildiren çalışmalar da bulunmaktadır (17,24-26). Bu farklılığın sebebi araştırmaya dahil olan hemşirelerin yoğun bakımda çalışma yıllarının çok olmaması ya da hemşirelerin hastalara bakım verirken uygun duruş pozisyonunda çalışmalarından kaynaklanıyor olabilir.

Kadınların fizyolojik, genetik, hormonal ve psikolojik yapıları kas yapısını ve gücünü olumsuz etkileyerek hasta kaldırma, taşıma gibi aktivitelerde kas iskelet sistemi sorunlarına neden olmaktadır (27). Çalışmamızda da benzer olarak diz hariç tüm vücut bölgelerinde kadınların erkeklere göre daha fazla kas iskelet ağrısı yaşadığ saptanmıştır (Tablo 2). Literatürde KISSR'in farklı yöntemlerle incelendiği çalışmalarda da benzer sonuçlar bulunmuştur (17,18,22,26, 28-30).

Literatürde BKI'nnin kas iskelet sistemi kaynaklı ağrıyı arttıran en önemli risk faktörlerinden biri olduğunu aktaran çalışmalar mevcuttur(6,18,27). BKİ artmasıyla kasın taşıdığı yük artacağından zorlanma nedenli ağrının oluşması beklenen bir durumdur (6, 17, 18). Ancak çalışmamızda hemşirelerin son 12 ay içerisindeki kas iskelet sistemi ağrı lokalizasyonları ile BKİleri arasında bir ilişki saptanmamıştır (her biri için; p > ,05; Tablo 2). Literatür incelendiğinde BKİ arttıkça KİS ağrısınına artması beklenen bir durum olmasına karşın, çalışmamızda BKİ $<24$ olan hemşirelerin tüm vücut bölgelerindeki ağrıları BKİ $>24$ olan hemşirelere göre daha fazla bulunmuştur. $\mathrm{Bu}$ durum BKI düşük hemşirelerin çalışırken vücut postürlerine dikkat etmelerinden kaynaklanıyor olabilir.

Çalışmamızda 3. basamak genel yoğun bakım ünitesinde çalışan hemşirelerin \%56,5'inde omuz ağrısı, koroner yoğun bakımda çalışan hemşirelerin \%55,6'sında ayak bileği / ayak ağrısı daha yüksek saptanmıştır (Tablo 2). Yoğun bakım ünitesinde bakım verilen hastaların farklı profilde olması bu farklılı̆̆ı sebebi olabilir. Çalışmamızdaki üçüncü basamak yoğun bakım ünitesinde hastaların çoğunun yatağa bağımlı ve tüm gereksinimleri yatak içinde hemşireler tarafindan karşılanırken, koroner yoğun bakım ünitesinde hastalar mobilize edilip hemşire yardımıyla yürütülmektedir. Bunun sonucunda hemşirelerin farklı vücut bölgelerindeki mekanik zorlanma sonucunda farklı vücut bölgelerinde ağrı ortaya çıkabilmektedir.

Aynı pozisyonda uzun süre çalışmak, yatağa bağımlı hastaları kaldırmak veya nakletmek (yatak-sedye) hemşirelerin kas iskelet sistemi rahatsılıklarıyla güçlü bir şekilde ilişki göstermektedir (31). Warming ve arkadaşları tarafından yapılmış olan bir çalışmada hemşirelerin fiziksel iş yüklerinin (hasta transferi) diz ağrısı üzerinde etkili olduğu, fiziksel iş yükleri ile çalışma ortamında karşılaştıkları psikososyal faktörlerin (stres) ise sırt ağrıları ile ilişkili olduğu bildirilmiştir (32).
Çalışmamızda hemşirelerden kas iskelet sistemlerinde ağrı şikâyetleri var olanların, kas iskelet sistemindeki ağrı lokalizasyonlarından boyun bölgesinde, omuz bölgesinde, sırt bölgesinde ve ayak-ayak bileğinde ağrısı olanların REBA puanları daha yüksektir (her biri için; p $<, 05$; Tablo 3). Hemşirelerin duruş pozisyonlarının REBA ile analiz edildiği bir çalışmada en fazla etkilenen vücut bölümlerinin sirasiyla bacak, bel, boyun, diz ve ayak bilekleri ile omuz bölgesi olduğu ve hemşirelerin bel, omuz, boyun ve diz ağrısı prevelanslarının yüksek olduğu bildirilmiştir $(31,33)$.

\section{Araştırmanın Sınırlılıkları}

- Hemşirelerin iş yükleri fazla olduğu için çalışmaya zaman ayırmak istememeleri,

- Gözlem esnasinda haberleri olmasa da gözlenecek olmalarını bilmeleri,

- Duruş analizinin tek bir işlem için yapılıyor olmas1,

- $\quad$ Araştırmanın tek bir hastanede yürütülmüş olması çalışmanın sınırlılıkları arasındadır.

\section{SONUC}

Çalışmamızda son 12 ay içerisinde hemşirelerin kas iskelet sistemi ağrılarının en sık görüldüğü üç lokalizasyon; \%56,1 ile bel, \%41,8 ile sirt ve \%39,8 ile boyun bölgeleri olarak saptanmıştır. Hemşirelerden kas iskelet sistemlerinde ağrı şikâyeti olanların, kas iskelet sistemindeki ağrı lokalizasyonlarından boyun bölgesinde, omuz bölgesinde, sırt bölgesinde ve ayak-ayak bileğinde ağrısı olanların REBA puanları daha yüksektir.

Hemşirelerin iş ile ilgili kas iskelet sistemi rahatsızlıklarını önlemek, risk seviyelerini azaltmak için yoğun bakımlardaki kullanılan ekipmanın ergonomik açıdan uygun olması yararlı olacaktır. Hemşirelerin var olan kas iskelet sistemi hastalıkları / rahatsızlıklarının ilerlemesini önlemek amacıyla doğru duruş, çalışma pozisyonu konularını içeren periyodik eğitim programlarının düzenlenmesi ve rahatsızlıklarına uygun egzersiz programlarına yönlendirilmeleri önerilmektedir. İş sağllğ 1 ve güvenliği biriminin ergonomi ekibi oluşturarak hemşirelerin meslekle ilişkili kas iskelet sistemi rahatsızlıklarına neden olabilecek işlemler için ergonomik risk analizlerinin yılda bir kez yapılarak değerlendirilmesi yararlı olacaktır.

Yazarların Katkıları: Fikir/Kavram E.A.Ö., Ö.Ö. Tasarım E.A.Ö., Ö.Ö. Veri Toplama ve/veya İşleme E.A.Ö. Analiz ve/veya Yorum E.A.Ö., Ö.Ö. Literatür Taraması E.A.Ö. Makale Yazımı E.A.Ö., Eleştirel İnceleme E.A.Ö., Ö.Ö.

\section{KAYNAKLAR}

1. WHO. WHO global plan of action on workers' health (2008-2017): Baseline for implementation. Geneva, Switzerland: World Health Organization; 2013.

2. Yılmaz E, Özkan S. Hastanede çalışan hemşirlerde bel ağrısı prevelensının saptanması. Turk J Physiother Rehabil. 2008; 54: 8-12.

3. Saygün M. Sağlık çalışanlarında iş sağlığı ve güvenliği sorunları. TAF Preventive Medicine Bulletin. 2012; 11(4): 373-82. 
4. Ceylan H, Başhelvacı VS. Risk değerlendirme tablosu yöntemi ile risk analizi: bir uygulama. International Journal of Engineering Research and Development. 2011; 3(2): 25-33.

5. Tambağ H, Can R, Kahraman Y, Şahpolat M. Hemşirelerin çalışma ortamlarının iş doyumu üzerine etkisi. Med J Bakirkoy. 2015; 11(4): 143-9.

6. Şirzai H, Doğu B, Erdem P, Yılmaz F, Kuran B. Hastane çalışanlarında işe bağlı kas iskelet sistemi hastalıkları: üst ekstremite problemleri. Med Bull Sisli Etfal Hosp. 2015; 49(2): 135-41.

7. Bitek DE, Akyol A. Yoğun bakım hemşirelerinin çalışma ortamına ilişkin algıları ile iş doyumları arasındaki ilişkiin incelenmesi. Yoğun Bakım Hemşireliği Dergisi. 2017; 21(1): 1-6.

8. Grap MJ, Munro CL. Quality 1mprovement in backrest elevation, improving outcomes in critical care. AACN Advanced Critical Care. 2005; 16(2): 133-9.

9. Arslan S, Taylan S, Gözüyeşil E. Hemşirelerin çalışma ortamı yaşam kaliteleri ve etik duyarlılıkları. İzmir Katip Çelebi Üniversitesi Sağlık Bilimleri Fakültesi Dergisi. 2017; 2(2): 21-6.

10. Menzel NN, Brooks SM, Bernard TE, Nelson A. The physical workload of nursing personnel: association with musculoskeletal discomfort. International Journal of Nursing Studies. 2004; 41(8): 859-67.

11. Esin NM, Sezgin D. Yoğun bakım ortamında çalışan güvenliği: yoğun bakım Hemşirelerinin Çalışma Ortamı ve Mesleki Riskleri. Yoğun Bakım Hemşireliği Dergisi. 2012; 16(1): 14-20.

12. Deniz F, Alçelik A, Yeşildal N, Mayda AS, Ayakta Şerifi B. Health survey and life habits of nurses who work at the medical faculty hospital at AIBU. TAF Preventive Medicine Bulletin. 2005; 4(2): 55-65.

13. Terzi B, Kaya N. Yoğun bakım hastasında hemşirelik bakımı. Yoğun Bakım Dergisi. 2011; 1: 21-5.

14. Shimizu HE, Couto DT, Merchan Hamann E, Branco AB. Occupational health hazards in icu nursing staff. Nursing Research and Practice. 2010: $1-6$.

15. Özcan E, Kesiktaş N. Mesleki Kas İskelet Hastalıklarından Korunma ve Ergonomi. İş Sağlığ1 ve Güvenliği Dergisi. 2000: 34; 3-7.

16. Uz-Tunçay S, Yeldan İ. Kas iskelet sistemi rahatsızlıklarıyla fiziksel inaktivite ilişkili midir? Ağr1, 2013; 25(4): 147-55. https://doi.org/ 10.5505/agri.2013.09825.

17. Abedini R, Choobineh A, Hasanzadeh J. Musculoskeletal load assessment in hospital nurses with patient transfer activity. International journal of occupational hygiene. 2013; 5(2): 39-45.

18. Gül A, Üstündağ $\mathrm{H}$, Kahraman $\mathrm{B}$, Purisa $\mathrm{S}$. Hemşirelerde kas iskelet ağrılarının değerlendirilmesi. Journal of Health Science and Profession-HSP. 2014; 1(1): 1-10.

19. Kahraman T, Genç A, Göz E. The nordic musculoskeletal Questionnaire: cross-cultural adaptation into Turkish assessing its psychometric properties. Disability and Rehabilitation. 2016; 38(21): 2153-60.
20. Hignett S, McAtamney L. Rapid entire body assessment(REBA). Applied Ergonomics. 2000; 31(2): 201-5.

21. Gürleyen E, Kahya E. Kombi montaj hattında reba yöntemi ile ergonomik risk analizi. Mühendislik Bilimleri ve Tasarım Dergisi. 2018; 6(0): 58-66.

22. Kahya E, Gülbandılar S, Gürleyen E. Nöroloji yoğun bakım ünitesinde çalışan hemşirelerin maruz kaldığı fiziksel zorlanmaların analizi. Ergonomi. 2018; 1(1): 39-48.

23. Soyuer F, Soyuer A. Yaşlılık ve fiziksel aktivite. Turgut Özal Tıp Merkezi Dergisi. 2008; 15(3): 21924.

24. Widanarko B, Legg S, Stevenson M, Devereux J, Eng A, Mannetje A, et al. Prevalence of musculoskeletal symptoms in relation to gender, age, and occupational/industrial group. International Journal of Industrial Ergonomics. 2011; 41(5): 56172.

25. Ratzon NZ, Bar-Niv NA, Froom P. The effect of a structured personalized ergonomic intervention program for hospital nurses with reported musculoskeletal pain: An assigned randomized control trial. Work 2016; 54: 367-77.

26. İlçe A. Study on work-related musculoskeletal disorders in intensive care unit nurses. Anatolian Journal of Clinical Investigation. 2014; 8(2): 68-76.

27. Cimbız A, Uzgören N, Aras Ö, Öztürk S, Elem E, Aksoy CC. Kas iskelet sisteminde ağriya ait risk faktörlerinin lojistik regresyon analizi ile belirlenmesi: pilot çalışma. Turk J Physiother Rehabil. 2007; 18(1): 20-7.

28. Abdollahzade F, Mohammadi F, Dianat I, Asghari E, Asghari Jafarabadi M, Sokhanvar Z. Working posture and its predictors in hospital operating room nurses. Health Promotion Perspectives. 2016; 6(1): 17-22.

29. Lederer V, Rivard M, SD. MT. Gender differences in personal and work-related determinants of returnto-work following long-term disability: a 5-year cohort study. Journal of Occupational Rehabilitation. 2012; 22(4): 522-31.

30. Lu JM, Twu LJ, Wang MJJ. Risk assessments of work-related musculoskeletal disorders among the TFT-LCD manufacturing operators. International Journal of Industrial Ergonomics. 2016; 52: 40-51.

31. Çalık BB, Atalay OT, Başkan E, Gökçe B. Bilgisayar kullanan masa başı çalışanlarında kas iskelet sistemi rahatsızlıkları, işin engellenmesi ve risk faktörlerinin incelenmesi. MÜSBED. 2013; 3(4): 208-14.

32. Karlqvist L, Tornqvist EW, Hagberg M, Hagman M, Toomingas A. Self-reported working conditions of VDU operators and associations with musculoskeletal symptoms: a cross-sectional study focussing on gender differences. International Journal of Industrial Ergonomics. 2002; 30: 277-94.

33. Goswami S, Ghosh S, Sahu S. Evaluation of ergonomic risk factors in manual patient handling tasks of Indian nurses. Ergonomics SA: Journal of the Ergonomics Society of South Africa. 2017; 29(1): 2-10. 